\title{
El uso del vendaje funcional resulta eficaz para el manejo de la artrosis de rodilla
}

\section{Objetivo}

Establecer el efecto terapéutico un vendaje de rodilla con respecto al dolor y la incapacidad en pacientes con síntomas de osteoartritis, y determinar si los beneficios se mantienen en el tiempo una vez suspendido este tratamiento.

\section{Diseño}

Ensayo clínico controlado aleatorizado, simple ciego, de tres semanas de duración y tres semanas de seguimiento posterior.

\section{Lugar}

Voluntarios de la comunidad reclutados por publicidad en los periódicos, Melbourne, Australia.

\section{Participantes}

Síntomas de artrosis según la definición del Colegio Americano de Reumatología, excluyendo a aquellos que habían recibido fisioterapia o una infiltración en los últimos seis meses o cirugía de rodilla.

\section{Intervención}

Estudio de tres ramas: vendaje funcional terapéutico, vendaje funcional control y sin vendaje. El vendaje funcional se realizó con dos tipos de cintas autoadhesivas: una "pre-cinta" hipoalergénica y otra rígida por encima de la primera. Se colocaron $2 \mathrm{~cm}$ por encima de la rótula para proveer deslizamiento medial, inclinación medial y anteroposterior de la rótula y otra sobre el tendón rotuliano para descargar la grasa infrapatelar o la bursa anserina. El grupo vendaje control usaba únicamente la cinta hipoalergénica en la misma ubicación que el grupo tratamiento con el fin de proveer un estímulo sensitivo. Todos los participantes continuaron sus tratamientos habituales pero no podían comenzar ninguno nuevo. Los vendajes fueron colocados por fisioterapeutas entrenados.

\section{Medición de resultados principales}

El resultado primario fue el cambio en el dolor medido en una escala visual analógica* de 11 puntos, tanto del dolor con el movimiento como durante una actividad agravante. El cambio en el dolor se calificaba en una escala de 5 puntos de: 1 (mucho peor) a 5 (mucho mejor). Los puntajes de 4-5 fueron considerados como mejoría. Los resultados secundarios de dolor e incapacidad eran otras escalas e índices de dolor (Mc Master, Western Ontario, SF36).

\section{Resultados principales}

El estudio incluyó a 87 pacientes. El grupo de vendaje terapéutico mostró una reducción del dolor significativamente mayor que los otros grupos, si bien se observó un beneficio no significativo en el grupo de vendaje control. Esta tendencia se observó tanto al finalizar la intervención como a las 6 semanas. En cuanto a los resultados secundarios, el grupo de vendaje terapéutico mostró una reducción significativamente mayor del dolor y la incapacidad respecto al grupo sin vendaje. A las 6 semanas ambos grupos con vendaje mostraron mejorías significativas comparados con el grupo sin vendaje.

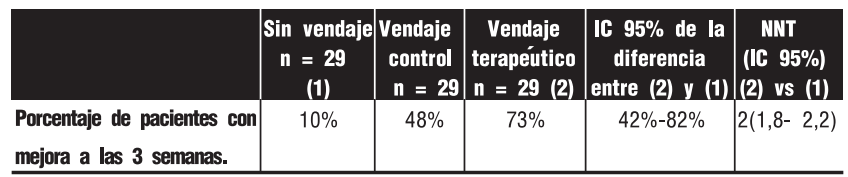

\section{Conclusiones}

El vendaje terapéutico fue un tratamiento eficaz para el manejo del dolor y la incapacidad en pacientes con artrosis de rodilla.

Fuente de financiamiento: Sin conflictos de interés

\section{Comentario}

El vendaje terapéutico de rodilla es una técnica sencilla, mediante la cual se aplica una tela adhesiva especial (o en su defecto la bien conocida cinta blanca) sobre la rodilla de manera tal de provocar el deslizamiento medial y anteroposterior de la rótula ${ }^{1,2}$. De esta manera se evita el dolor que provoca el rozamiento de la misma con el fémur cuando hay artrosis. Este trabajo demuestra que esta intervención produce una mejoría clínicamente significativa del dolor y la incapacidad respecto de los otros dos grupos controles, y que los beneficios pueden mantenerse tres semanas luego de suspender el tratamiento. El impacto clínico de las diferencias fue de mediano a grande para la mayoría de los resultados, lo cual es comparable con el reportado por programas de ejercicio, drogas y fisioterapia.

En cuanto a la población beneficiada, es interesante que, a diferencia de estudios previos, la misma incluía a pacientes con enfermedad de diferente severidad radiológica y afectación variada de la articulación (inclusive pacientes sin afectación patelar), lo cual contribuiría a generalizar la intervención a más pacientes. En líneas generales la población tenía artrosis moderadamente severa y reportaba dolor e incapacidad moderados. Incluía más mujeres que hombres, y a obesos hasta un índice de masa corporal de 38. No incluía pacientes con piel frágil ni alérgicos a la cinta.
En cuanto a la técnica, no es necesario que sea un especialista quien realice la intervención, e incluso podría entrenarse a los pacientes para auto-aplicarse la cinta, si bien esto no ha sido probado todavía. La principal limitación de este estudio sería su corta duración, ya que estamos hablando del tratamiento de una condición crónica. Sin embargo, aunque esta es una intervención breve y con resultados medidos a corto plazo, esta mejoría temporal de los síntomas permitiría que el paciente realice ejercicio y reacondicione su musculatura. En nuestra experiencia tuvimos la oportunidad de utilizar este tratamiento usando tela adhesiva común, que se puede conseguir en cualquier hospital, y obtuvimos una mejoría significativa del dolor y la función articular en pacientes con artrosis de rodilla.

\section{Conclusiones de los comentadores}

El vendaje terapéutico demostró ser una intervención simple y efectiva a corto plazo para disminuir el dolor en pacientes con artrosis de rodilla moderada a severa. Puede ser realizado por médicos de familia o generales y posiblemente por los pacientes.

\section{Dr. Gabriel Kñallevsky y Dr. Ricardo Frusso [ Unidad de Medicina Familiar y Preventiva. Hospital Italiano de Buenos Aires. ]}

Kñallevsky G, Frusso R. El uso del vendaje funcional resulta eficaz para el manejo de la artrosis de rodilla. Evid. Actual.práct.ambul.2005;8:9.Comentado de: Efficacy of knee tape in the management of osteoarthritis of the knee: blinded randomised controlled trial. Hinman RS, Crossley KM, McConnell J, et al. BMJ 2003;327:135. PMID 12869456

\section{Referencias}

1. Pendleton A, Arden N, Dougados M, Doherty M, Bannwarth B, Bijlsma JWJ, et al. EULAR recommendations for the management of knee osteoarthritis: report of a task force of the Standing Committee for International Clinical Studies Including Therapeutic Trials (ESCISIT). Ann Rheum Dis 2000;59: 936-44.

2. Cushnaghan J, McCarthy C, Dieppe P. Taping the patella medially: a new treatment for osteoarthritis of the knee joint? BMJ 1994;308: 753-5 